\title{
Heterogeneity of Human Platelets
}

\author{
I. METABOLIC AND KINETIC EVIDENCE \\ SUGGESTIVE OF YOUNG AND OLD PLATELETS
}

\author{
Simon KarPatKIN with the technical assistance of \\ Arthur Charmatz \\ From the Department of Medicine, New York University Medical Center, \\ New York 10016
}

\begin{abstract}
A B S T R A C T Human platelets have been separated into two extreme density populations by centrifugation in specific density media. A large-heavy platelet population with specific gravity $>1.055$ and a light-small population with specific gravity $<1.046$ were obtained, each representing approximately $15-20 \%$ of the total population volume. The average volume per platelet of the separated large-heavy and light-small platelet populations was 12 and $5 \mu^{8}$ respectively. When data are expressed per milliliter platelets or per gram wet weight, the large-heavy platelet population had a 2 -fold greater glycogen content, 1.3-fold greater orthophosphate content, 1.3-fold greater total adenine nucleotide content, 4.2-fold greater rate of glycogenolysis, 2.6-fold greater rate of glycolysis, 2.9-fold greater rate of protein synthesis, and 5.7-fold greater rate of glycogen synthesis. Significant differences were not obtained with respect to total lipid content or total lipid synthesis. The large-heavy platelet had a 2.5-fold greater resistance to osmotic shock as measured by adenosine triphosphate (ATP) or adenosine diphosphate (ADP) release.

These data, as well as diisopropyl fluorophosphate $\left(\mathrm{DFP}^{82}\right)$ survival curves in rabbits, indicate that largeheavy platelets have a greater metabolic potential and suggest that they may be the young platelets which progress with age to light-small platelets with a diminished metabolic potential.
\end{abstract}

\section{INTRODUCTION}

The human platelet is a unique element of the blood, in that its major physiological function is geared to its

\footnotetext{
A preliminary abstract appeared in $1968 \mathrm{~J}$. Clin. Invest. 46: $52 \mathrm{a}$.

Dr. Karpatkin is a Career Scientist of the Health Research Council of the City of New York (I-459).

Received for publication 2 December 1968 and in revised form 6 February 1969.
}

destruction and death. It has consequently been proposed that platelets do not die of senescence, but are removed in a random fashion. This thesis is dependent upon continual platelet utilization, necessary for the repair of injured endothelial surfaces as well as maintenance of hemostasis.

Isotopic platelet survival data have provided considerable controversy as to whether platelet disappearance curves are linear (senescent removal [1-6]) or exponential (random removal [7-9]) when plotted arithmetically. More recent platelet survival studies suggest a mixed picture of both senescent and random destruction (10).

This study was initiated to determine whether biochemical data could be obtained to provide evidence for human platelet senescence. Human platelets were separated into two extreme density populations (heavy-large and light-small) by centrifugation in specific density media. These two populations, as well as the total platelet population, were then analyzed for their composition of: adenosine triphosphate (ATP), adenosine diphosphate (ADP), adenosine monophosphate (AMP), orthophosphate, glycogen, lipid, and protein. Further studies were performed on platelet glycogenolysis, glycolysis, glucose uptake, and incorporation of $\mathrm{C}_{14}$ glucose into glycogen, as well as lipid. The two platelet populations were also examined for their resistance to osmotic shock.

Kinetic measurements of in vivo diisopropyl fluorophosphate $\left(\mathrm{DFP}^{\mathrm{s} 2}\right)$-labeled rabbit platelet populations were also obtained.

\section{METHODS}

Preparation of platelets. Human platelets were collected and processed as described previously $(11,12)$. Human Ringer's solution contained the same electrolytes as described previously, except for the addition of $20 \mathrm{~mm} \mathrm{NaCl}$ to give a final concentration of $117 \mathrm{mmoles} /$ liter (imple- 
mented to obtain perfect isotonicity as measured with an Advanced osmometer).

Separation of platelets into heavy-large and light-small populations. This was achieved by layering $6-10 \mathrm{ml}$ of a $7-10 \%$ suspension of $4^{\circ} \mathrm{C}$ washed platelets over $0.5 \mathrm{ml}$ of a fixed-density oil mixture kept at room temperature in a $12 \mathrm{ml}$ plastic centrifuge tube, $3 \times 5 / 8$ inches. The centrifuge tube was then centrifuged for $4 \mathrm{~min}$ at $5900 \mathrm{~g}$ at $4^{\circ} \mathrm{C}$ in a Sorvall RC-2 centrifuge, employing an SS-34 angle head. The fixeddensity mixture was composed of a mixture of two relatively inert oils: $n$-dibutyl phthalate, sp gr 1.0564, and Apiezon A oil, ${ }^{1}$ sp gr 0.8788 . Both oils were highly miscible and with careful volumetric and weight measurements at room temperature, oil mixtures of sp gr 1.0459 and 1.0544 could be obtained. These mixtures maintained the same specific gravity when stored in tightly capped glass scintillation vials and held in a dessicator at room temperature for at least 1 month. The lower specific gravity mixture was employed to separate small-light platelets, i.e., the platelets remaining on the surface of the Apiezon A oil-dibutyl phthalate mixture were harvested and those platelets falling to the bottom of the tube discarded. The higher specific gravity mixture was employed to separate large-heavy platelets, i.e., the platelets falling to the bottom of the centrifuge tube were harvested and those remaining on top of the Apiezon A oil-dibutyl phthalate mixture discarded. Recentrifugation of high or low specific gravity platelet populations resulted in reisolation of all the platelets at the same location in the centrifuge tube as before. Control experiments revealed that passage of platelets through the oil mixture had no effect on platelet adenine nucleotide content, lactate production, or glucose uptake: i.e., a platelet suspension was divided into two aliquots; one aliquot, the control, was not processed, whereas a second aliquot was processed for separation into a largeheavy, light-small, and residral platelet population; the three populations of the processed aliquot were then recombined and compared to the unprocessed control population as above.

The separated top and bottom specific gravity platelet populations were washed once in human Ringer's solution$0.1 \mathrm{mM}$ ethylenediaminetetraacetate (EDTA), approximately 20 volumes of wash to one volume of platelets. This separation procedure was performed before measurements of the platelet contents: ATP, ADP, AMP, orthophosphate, and glycogen. It was also employed before incubation of these platelet populations for measurement of lactate production and glucose uptake, as well as for studies measuring resistance to osmotic shock.

Experiments involving incorporation of radioactive leucine $-{ }^{14} \mathrm{C}$ or glucose $-{ }^{14} \mathrm{C}$ into platelet constituents were performed on a total washed-platelet population which, after termination of the incubation, was then separated by the above treatment into the two extreme density populations. Under these conditions, the specific gravity mixtures which were required for optimum separation were 1.044 for light-small platelets and 1.052 for large-heavy platelets.

Preparation of samples. For the measurement of intracellular ATP, ADP, AMP, and orthophosphate, as well as extracellular ATP, ADP, lactate, and glucose, neutralized

${ }^{1}$ Obtained from Shell International Chemical Co., Ltd., Shell Centre, London, S.E. 1. The Apiezon A oil contains a mixture of high molecular weight hydrocarbons with average molecular weight of 414 , approximately equivalent to triacontane. They are mainly paraffin or isoparaffinic, but there is also a fairly high per cent of cyclic paraffins and a small content of high molecular weight aromatics. perchloric acid extracts were employed as described previously $(11,12)$. Platelet volumes were measured in microhematocrit tubes as described previously (11). Platelet counts of washed platelets were determined, after suitable dilutions, on Spencer Bright-Line counting chambers employing phase microscopy.

Assay procedures. Standards were run with all assays. These were linear with increasing concentration over the range measured. Addition of standard to platelet extract resulted in recovery of better than $90 \%$ for all assays. All enzymatic measurements were performed with a BeckmanGilford spectrophotometer employing nucleotide changes at 363 and $340 \mathrm{~m} \mu$ for acetyl nicotinamide adenine dinucleotide (AcNAD) and NAD, respectively. These are minor modifications of the methods of Lowry et al. (13). All measurements were performed in triplicate. Lactate, glucose, and ATP were measured as described previously (11). ADP was measured by coupling the pyruvate kinase reaction with the lactic dehydrogenase reaction and measuring the NADH to NAD change at $340 \mathrm{~m} \mu$ (12). AMP was measured by coupling the myokinase reaction to the above ADP assay (12). Commercial NADH contained significant amounts of AMP. This was measured as a blank and subtracted from the sample reading.

Glycogen was measured by a minor modification of that described by Hassid and Abraham (14). Glycogen molarity is expressed as glucose units.

Intracellular orthophosphate was measured as described previously $(12,15)$.

Protein was measured with the biuret reagent, employing bovine serum albumin as standard.

Total lipid was measured by a gravimetric procedure in tared-weighing vials after chloroform-methanol (16) extraction and subsequent gentle evaporation.

Incubations. Platelet suspensions were incubated at $37^{\circ} \mathrm{C}$ under $95 \% \mathrm{O}_{2}-5 \% \mathrm{CO}_{2}$ for varying time intervals. For radioactive experiments, approximately $1.5-2 \mathrm{ml}$ of packed platelets were suspended in human Ringer's solution-0.1 mM EDTA in a volume of $30-40 \mathrm{ml}$ and incubated in tightly capped plastic tubes shaken at $25 \mathrm{rpm}$. For lactate production and glucose uptake experiments, incubations were performed with approximately $0.25-0.3 \mathrm{ml}$ of packed platelets which were suspended in a volume of 5-6 ml. Incubations were performed in duplicate and terminated by centrifugation of the incubation tubes at $3000 \mathrm{~g}$ for $10 \mathrm{~min}$ at $4^{\circ} \mathrm{C}$. For further details, see reference 11 .

Isotope experiments. Platelets were incubated as described above in the presence of sufficient uniformly labeled leucine $-{ }^{14} \mathrm{C}$ or uniformly labeled glucose $-{ }^{14} \mathrm{C}$ to provide $1 \times 10^{\circ} \mathrm{cpm} / \mathrm{ml}$ incubation fluid for both. Nonlabeled leucine or glucose was added to the incubation media to achieve the desired concentration. See results.

After termination of incubation, platelet extracts were made (see below) and their radioactivity determined in glass counting vials containing Bray's solution (17). The radioactivity was determined in a Beckman LS100 scintillation spectrometer with isolet adjusted to give $98 \%$ counting efficiency. The radioactivity in the experimental platelet extract samples was 6-16 times above background, $45 \mathrm{cpm}$, with sufficient counts obtained to give a counting error of less than $3 \%$. Control experiments showed no interference with counting efficiency by the addition of the various unlabeled platelet extracts to a standard quantity of radioactivity. The volume of sample employed for radioactivity measurements was well within the equal linear range of sample volume addition vs. radioactivity obtained.

Platelet extraction procedure for isotopic incubation ex- 
periments. After termination of a radioactive incubation, platelets were washed three times with human Ringer's solution-0.1 mM EDTA to a constant supernatant radioactivity. They were then separated into the two extreme density-volume populations. The platelet population fractions were then individually treated by the following procedures: the separated platelet suspensions were transferred to $50-\mathrm{ml}$ plastic tubes which were centrifuged at $2000 \mathrm{~g}$ for $10 \mathrm{~min}$ to remove the human Ringer's solution; the pellet was then treated by the procedure of Folch, Lees, and Sloane Stanley (16) with 20 times its volume of chloroform-methanol (2:1) and held over a Vortex mixer for $1 \mathrm{~min}$. The platelet homogenate in its centrifuge tube was then stored overnight at $4^{\circ} \mathrm{C}$. It was next centrifuged at $2000 \mathrm{~g}$ for $10 \mathrm{~min}$ and separated into a sediment and a chloroform-methaol extract.

Sediment. The sediment was treated by the Schneider procedure (18).

Chloroform-methanol (2:1) supernatant. This was extracted twice by the Folch procedure (16). The combined aqueous solutions contained significant radioactivity which was soluble in chloroform-methanol. Accordingly, it was necessary to extract the combined aqueous solution once, with an equal volume of chloroform-methanol. The combined chloroform-methanol solution was gently evaporated to dryness and the lipid content determined gravimetrically. The dry lipid was then dissolved in $0.5 \mathrm{~N} \mathrm{NaOH}(5 \mathrm{ml} \mathrm{NaOH} / 0.2$ $\mathrm{ml}$ platelets) and the material utilized for radioactivity as well as protein determination. The protein content was less than $4.5 \%$ of total platelet protein ( 22 experiments).

Glycogen platelet extracts. These were obtained in a manner similar to that described by Hassid and Abraham (14).

Studies on resistance to osmotic shock. The platelet pellets consisting of the two extreme density-volume populations were gently suspended in varying concentrations of a cold $\mathrm{NaCl}$-glucose solution containing $5 \mathrm{~mm}$ glucose, plus $0.5,0.4$, and $0.3 \mathrm{~g} / 100 \mathrm{ml} \mathrm{NaCl}$. The suspensions $(5 \%$ by volume) were then incubated for $5 \mathrm{~min}$ at $37^{\circ}$ at $25 \mathrm{rpm}$. At the termination of the experiment, the platelets were centrifuged at $2000 \mathrm{~g}$ for $10 \mathrm{~min}$. An aliquot of the supernatant solution was then diluted $1: 10$ in respective $\mathrm{NaCl}$ glucose solution and its optical density immediately determined at 280 and $260 \mathrm{m \mu}$. A second aliquot was treated with perchloric acid, neutralized, and assayed enzymatically for ATP and ADP. These incubation conditions were found to be optimum for demonstrating differences in platelet response to osmotic shock. The conditions which had been varied were: ionic strength, presence or absence of glucose, and duration of incubation.

Isotopic platelet survival data in rabbit platelet population. Six white New Zealand rabbits weighing 4-5 kg were injected by ear vein with $0.072 \mathrm{mg} / \mathrm{kg} \mathrm{DFPa}, 9.4 \mu \mathrm{c} / \mathrm{kg}(10)$; this results in the labeling of the entire population of platelets. One animal was sacrificed daily by exsanguination on days 1-5. The internal carotid artery was cannulated with a plastic catheter and approximately $140 \mathrm{ml}$ of blood collected in ACD solution. Platelet-rich plasma and platelet pellet were prepared in a manner similar to that for human material. The platelet pellet was suspended in human Ringer's- $0.1 \mathrm{~mm}$ EDTA, resedimented, and resuspended in $30 \mathrm{ml}$ of $1 \%$ ammonium oxalate. This procedure was repeated and served to remove contaminating labeled red blood cells. This suspension was then utilized to separate rabbit platelets into extreme density-volume populations as described for human platelets. The optimal specific gravity oil mixtures for rabbit platelets were 1.0564 and 1.0480 for heavy-large and light-small platelets, respectively. These separated populations were washed in human Ringer's -0.1 mM EDTA. Platelet volume and count were determined and the separated populations were sedimented at $2000 \mathrm{~g}$ for $10 \mathrm{~min}$. The pellets were dissolved in $0.5 \mathrm{ml}$ hyamine hydroxide and counted for radioactivity. All samples were counted simultaneously to correct for the decay of "P. The radioactivity for all samples was at least 3.5 times background, $74 \mathrm{cpm}$, with a counting error of less than $2 \%$.

Materials. Distilled, deionized water was used at all times. All chemicals were reagent grade. Glucose 6-phosphate dehydrogenase, EDTA, NADP, acetyl NAD, ATP, and ADP were obtained from Sigma Chemical Co., St. Louis, Mo. Pyruvate kinase, hexokinase, phosphoenolpyruvate, and $\mathrm{NADH}$ were obtained from Boehringer Mannheim Corp., New York. Beef heart lactic dehydrogenase was obtained from Worthington Biochemical Corp., Freehold, N. J. Shellfish glycogen and n-dibutyl phthalate were obtained from Fisher Scientific Company, New York. Puromycin was obtained from Nutritional Biochemicals Corporation, Cleveland, Ohio. Uniformly labeled leucine- ${ }^{16} \mathrm{C} 311 \mu \mathrm{c} / \mu \mathrm{m}$, uniformly labeled glucose- ${ }^{14} \mathrm{C}, 307 \mu \mathrm{c} / \mu \mathrm{m}$, and diisopropyl fluorophosphate $\left(\mathrm{DFP}^{22}\right), \quad 7.17 \mu \mathrm{c} / \mu \mathrm{m}$ were obtained from Nuclear-Chicago Corporation, Des Plaines, Ill. Apiezon A oil was obtained from James G. Biddle Co., Plymouth Meeting, $\mathrm{Pa}$. Hyamine hydroxide was obtained from Packard Instrument Co., Downers Grove, Ill.

\section{RESULTS}

In all experiments, the two extreme density-volume populations were compared with the total population of which they were fractions. In 77 different experiments, each representing freshly collected platelet pools from three to four donors, the average total population of platelets contained $0.783 \times 10^{11}$ platelets $/ \mathrm{g}$ wet weight (or milliliter packed platelets).? The large-heavy population contained $0.498 \times 10^{11}$ and the small-light population contained $1.16 \times 10^{11}$ platelets. From the number of platelets per volume, and the extracellular space of the packed platelet pellet (19), one can calculate the volume per platelet of large-heavy, total, and light-small platelets: $11.8,7.52$, and $5.08 \mu^{8}$, respectively. The largeheavy platelets which were separated represented an average of $17.8 \%$ of the total platelet population volume while light-small platelets represented an average of $16.9 \%$ of the total platelet population. The average difference in volume between the large-heavy and lightsmall platelets was 2.3-fold.

Content of glycogen, orthophosphate, ATP, ADP, and $A M P$. The glycogen and orthophosphate content, as well as the adenine nucleotide content of these platelet populations, are illustrated in Table I. Glycogen, orthophosphate, ATP, and AMP concentration were considerably larger for large-heavy platelets than for lightersmaller platelets when data were expressed per platelet. These differences could not be attributed to differences in platelet volume, since the heavy/light ratios for glycogen, orthophosphate $\left(P_{1}\right)$, ATP, and AMP were 2.0, 1.3, $1.2(P<0.01)$, and 1.5-fold greater than their

\footnotetext{
'All data given in this paper have an SEM of less than $10 \%$.
} 
TABLE I

Glycogen, Adenine Nucleotide, and Orthophosphate Content per Platelet*

\begin{tabular}{|c|c|c|c|c|c|}
\hline & $\begin{array}{l}\text { Light } \\
19 \% \ddagger\end{array}$ & $\begin{array}{l}\text { Total } \\
100 \%\end{array}$ & $\begin{array}{c}\text { Heavy } \\
16 \%\end{array}$ & Heavy/light ratio & Platelet volume ratio \\
\hline Glycogen $(10) \S$ & 23.3 & 43.3 & 91.6 & 3.90 & 1.98 \\
\hline \multirow[t]{2}{*}{$P_{i}(9)$} & 2.42 & 2.03 & 5.39 & 2.20 & 1.70 \\
\hline & $\begin{array}{c}\text { Light } \\
16 \%\end{array}$ & $\begin{array}{l}\text { Total } \\
100 \%\end{array}$ & $\begin{array}{c}\text { Heavy } \\
21 \%\end{array}$ & Heavy/light ratio & Platelet volume ratio \\
\hline $\operatorname{ATP}(6)$ & 2.08 & 3.45 & 5.90 & 2.84 & 2.38 \\
\hline $\mathrm{ADP}(5)$ & 1.73 & 2.29 & 3.80 & 2.20 & 2.38 \\
\hline $\mathrm{AMP}(5)$ & 0.353 & 0.632 & 1.27 & 3.60 & 2.38 \\
\hline
\end{tabular}

* Given as $\times 10^{-11} \mu \mathrm{m} /$ platelet.

$\ddagger$ Refers to the relative volume of the particular platelet population with respect to the total population.

$\$$ Number of experiments is given in parentheses, SEM for all measurements was less than $10 \%$. Individual adenine nucleotide measurements were assayed in triplicate. Glycogen and orthophosphate were assayed in duplicate.

respective platelet volume ratios. The ADP heavy/light ratio was not significantly different from the platelet volume ratio.

Glycogenolysis, glycolysis, and glucose uptake. Largeheavy platelets have a glycolytic rate which is 4.2 -fold greater than light-small platelets in the absence of glucose (Fig. 1). This rate probably represents glycogenolysis and can be attributed to the twofold greater glycogen content of the large-heavy platelets (per gram wet weight). In the presence of glucose, the large-heavy

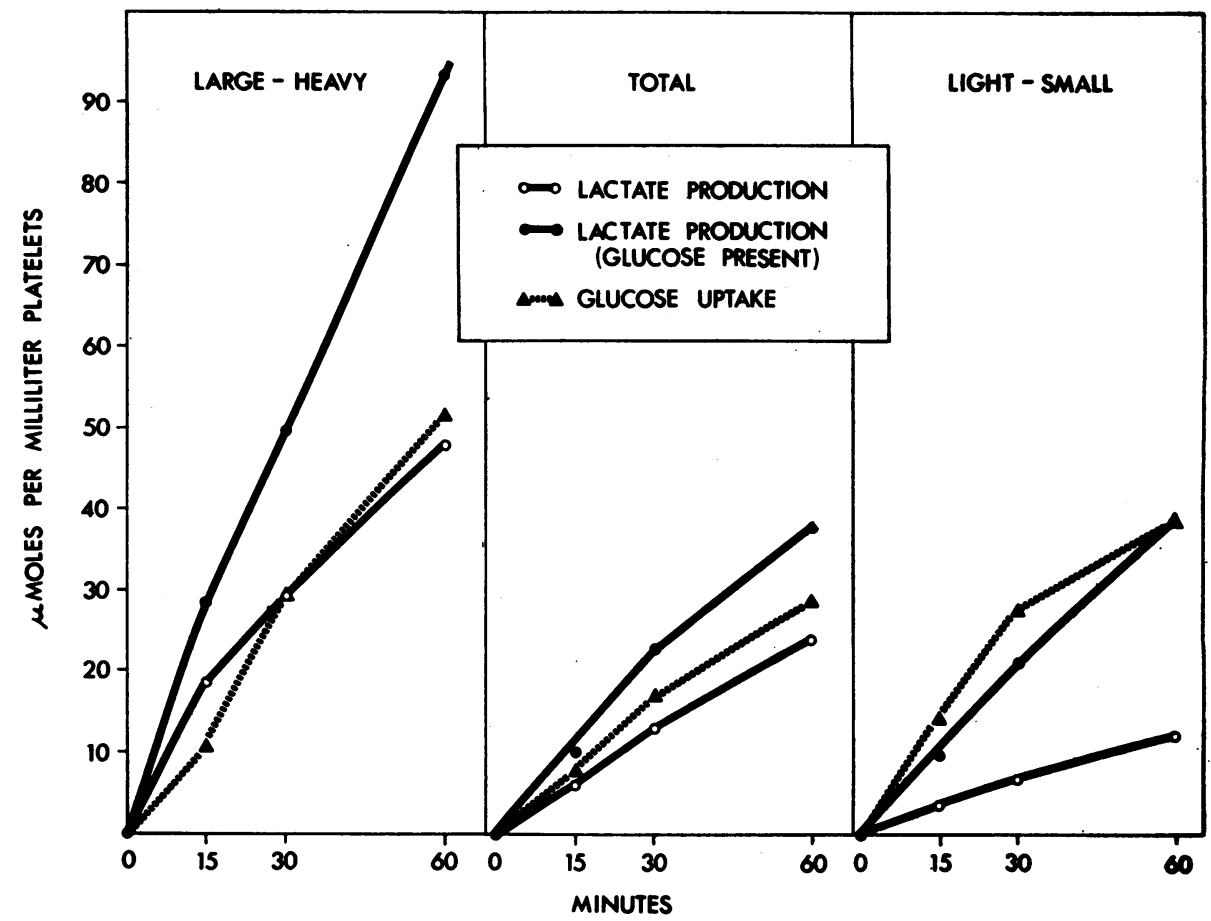

FIGURE 1 Lactate production and glucose uptake of separate platelet populations. Human platelets were separated into extreme density populations and incubated at $37^{\circ} \mathrm{C}$ for 15,30 , and $60 \mathrm{~min}$. Large-heavy platelets, $25 \%$ of total volume, light-small platelets, $17 \%$ of total volume, and a total population, $100 \%$ of total volume are compared. The platelet volume ratio of large-heavy/light-small platelets was 1.9. Data are expressed as micromoles per milliliter packed platelets. Each point represents a minimum of five experiments, incubated in duplicate and assayed in triplicate. SEM was less than $10 \%$. 
TABLE II

Effect of Puromycin on the Incorporation of Leucine ${ }^{-14} \mathrm{C}$ into a Platelet Protein Extract

\begin{tabular}{ccrcc}
\hline Experiment* & Puromycin & Control & Puromycin & Inhibition \\
\hline & $\mu g / m l$ & $c p m / g m$ & $c p m / g m$ & $\%$ \\
1 & 100 & 8,025 & 2400 & 70 \\
2 & 200 & 10,000 & 2475 & 75 \\
3 & 200 & 6,700 & 1800 & 73 \\
4 & 300 & 12,675 & 3700 & 71 \\
$5 \ddagger$ & 200 & 7,000 & 975 & 86 \\
\hline
\end{tabular}

* All incubations as well as radioactivity measurements were performed in duplicate.

$\ddagger$ Preincubated with puromycin for $15 \mathrm{~min}$ before addition of leucine ${ }^{-14} \mathrm{C}$ for $1 \mathrm{hr}$.

platelets also had a glycolytic rate which was 2.6 -fold greater than the light-small platelets. Glucose uptake was not significantly greater. Of interest are the differences between total and light-small platelet populations. As is apparent, lactate production in the absence of glucose (glycogenolysis) was 1.9-fold greater in total platelets, yet lactate production in the presence of glucose was the same for both total and light-small platelet populations. However, glucose uptake was 1.5 -fold greater for the light-small platelets. These data suggest that in the presence of glucose, regulatory mechanisms can maintain lactate production (and consequent ATP generation) despite a diminished rate of glycogenolysis. Alternatively, this increased glucose uptake could also be explained on the basis of a greater plasma membrane surface area for light-small platelets per packed platelet volume.

Incorporation of leucine $-{ }^{14} C$ into a platelet protein extract. The protein concentration of a total population of platelets was $119 \mathrm{mg} / \mathrm{g}$ wet weight (average of 22 experiments). The protein concentration of the heavylarge platelet population was $121 \mathrm{mg} / \mathrm{g}$ compared to $107 \mathrm{mg} / \mathrm{g}$ for light-small platelet population. This small difference between heavy-large and light-small platelet population was highly significant $(P<0.01)$.

Before measuring the incorporation of leucine $-{ }^{14} \mathrm{C}$ into platelet protein extract, it was first necessary to estab- lish the validity of protein synthesis as well as the degree of protein synthesis when compared to other tissues. Platelets were incubated in the presence of extracellular leucine, $0.025 \mu \mathrm{m} / \mathrm{ml}$, for $1 \mathrm{hr}$ at $37^{\circ} \mathrm{C}$ with and without puromycin. After lipid extraction, aminoacyl RNA extraction, the incorporation of ${ }^{14} \mathrm{C}$ into residual platelet protein was investigated, Table II. As can be noted, the incorporation of leucine $-{ }^{14} \mathrm{C}$ into a platelet protein extract was inhibited up to $86 \%$ when $200 \mu \mathrm{g} / \mathrm{ml}$ extracellular puromycin was exposed to platelets $15 \mathrm{~min}$ before incubation with leucine- ${ }^{14} \mathrm{C}$.

The extent of incorporation of leucine $-{ }^{14} \mathrm{C}$ into platelet protein was next investigated. In five experiments with an extracellular leucine concentration of $0.2 \mu \mathrm{m} / \mathrm{ml}$, $0.025 \%$ leucine $-{ }^{14} \mathrm{C}$ was incorporated into $1 \mathrm{~g}$ wet weight of platelets."

Separate platelet populations were incubated in the presence of leucine- ${ }^{14} \mathrm{C}$, one million $\mathrm{cpm} / \mathrm{ml}$ for $1 \mathrm{hr}$ of incubation. Significant differences were noted between heavy-large and light-small platelets when data were expressed per platelet. These differences were absolute and could not have been secondary to differences in platelet volume, i.e., specific activity, heavy/light ratio of 2.7 , Table III.

Incorporation of leucine $-{ }^{14} \mathrm{C}$ into a platelet lipid fraction. The lipid concentration of a total population of platelets was $29.8 \mathrm{mg} / \mathrm{g}$ wet weight (average of $22 \mathrm{ex}$ periments). Similar values were obtained from largeheavy and light-small platelets, 30.5 and 29.6 , respectively.

Incubation of platelets with leucine $-{ }^{14} \mathrm{C}$, in the presence of puromycin, Table IV, did not inhibit incorporation into the lipid fraction. This observation makes it very unlikely that incorporation of leucine $-{ }^{14} \mathrm{C}$ was into the protein moiety of the $4.5 \%$ lipoprotein present in this fraction. Of interest was the enhanced incorporation of

\footnotetext{
${ }^{3}$ This may be compared with a similar experiment performed with frog sartorius (20) at $30^{\circ} \mathrm{C}$ in which per cent incorporation of extracellular $0.2 \mu \mathrm{m} / \mathrm{ml}$ leucine was $9.1 \%$ or 364-fold greater. Thus, the magnitude of platelet protein synthesis is minimal and its physiologic significance remains uncertain.
}

TABLE III

Incorporation of Leucine ${ }^{-14}$ C into a Platelet Protein Extract*

\begin{tabular}{|c|c|c|c|c|c|c|}
\hline $\begin{array}{l}\text { Extracellular } \\
\text { concentration }\end{array}$ & & $\begin{array}{l}\text { Light } \\
15 \% \ddagger\end{array}$ & $\begin{array}{l}\text { Total } \\
100 \%\end{array}$ & $\begin{array}{c}\text { Heavy } \\
17 \%\end{array}$ & $\begin{array}{l}\text { Heavy/light } \\
\text { ratio }\end{array}$ & $\begin{array}{c}\text { Platelet volume } \\
\text { ratio }\end{array}$ \\
\hline \multirow{3}{*}{$2 \mu \mathrm{m} / \mathrm{ml}$} & Protein, mg per platelet & 89.1 & 134 & 230 & 2.58 & 2.40 \\
\hline & cpm per platelet & 2628 & 8001 & 18,405 & 7.00 & 2.40 \\
\hline & $\mathrm{cpm} / \mathrm{mg}$ protein & 29.5 & 59.7 & 80.0 & 2.71 & \\
\hline
\end{tabular}

* Data are expressed per platelet $\times 10^{-11}$ or as $\mathrm{cpm} / \mathrm{mg}$ protein. Each measurement represents the average of four to five experiments which were both incubated and assayed for radioactivity in duplicate. SEM was less than $10 \%$.

$\ddagger$ Refers to the relative volume of the particular platelet population with respect to the total population. 
TABLE IV

Effect of Puromycin on the Incorporation of Leucine ${ }^{-14} C$ into a Platclet Lipid Extract

\begin{tabular}{ccccc}
\hline Experiment* & Puromycin & Control & Puromycin & Enhancement \\
\hline & $\mu g / m l$ & $c p m / g m$ & $c p m / g m$ & $\%$ \\
1 & 100 & 12,125 & 16,425 & 35 \\
2 & 200 & 12,150 & 28,425 & 134 \\
3 & 200 & 14,575 & 21,825 & 50 \\
4 & 300 & 27,850 & 34,075 & 22 \\
$5 \ddagger$ & 200 & 15,300 & 30,500 & 100 \\
\hline
\end{tabular}

* All incubations as well as radioactivity measurements were performed in duplicate.

$\ddagger$ Preincubated with puromycin for $15 \mathrm{~min}$ before addition of leucine ${ }^{-14} \mathrm{C}$ for $1 \mathrm{hr}$.

leucine- ${ }^{14} \mathrm{C}$ into the lipid fraction in the presence of puromycin.

Separate platelet populations were incubated in the presence of leucine- ${ }^{14} \mathrm{C}$ and extracted for lipid after $1 \mathrm{hr}$ of incubation, Table V. Data are expressed similar to Table III. As can be noted, significant differences between heavy-large and light-small platelet populations were only obtained when data were expressed per platelet. These differences were not absolute and could be attributed to the difference in platelet volume between the two extreme density population groups.

Incorporation of glucose ${ }^{14} \mathrm{C}$ into a platelet lipid extract. Incubation of platelets with glucose $-{ }^{14} \mathrm{C}, 5$ mmoles/liter, in the presence of puromycin, $200 \mu \mathrm{g} / \mathrm{ml}$, did not inhibit incorporation into the lipid fraction, i.e., control vs. puromycin incorporation was 13,531 and $15,781 \mathrm{cpm} / \mathrm{gm}$ wet weight, respectively, for the average of four experiments. These observations again make it unlikely that incorporation of glucose ${ }^{14} \mathrm{C}$ was into the protein moiety of the $4.5 \%$ lipoprotein present in this fraction.

Separate platelet populations were incubated in the presence of glucose- ${ }^{14} \mathrm{C}, 5 \mathrm{mmoles} / \mathrm{liter}$, one million $\mathrm{cpm} / \mathrm{ml}$, and extracted for lipid after $1 \mathrm{hr}$ of incubation. As can be noted from Table VI, similar results were obtained with glucose as were obtained with leucine.
Again, significant differences between heavy-large and light-small populations were not absolute.

Incorporation of glucose ${ }^{14} \mathrm{C}$ into platelet glycogen. When separate platelet populations were incubated in the presence of $5 \mathrm{~mm}$ glucose as above, considerable differences were noted with respect to the incorporation of glucose into glycogen, Table VII. Thus, the heavy/ light platelet population ratio incorporation was 13.7 which was considerably greater than the heavy/light platelet volume ratio of 2.4. This was an absolute difference and could not be attributed to a difference in platelet volume. It should be noted that the specific activity ratio was also significantly greater than one, despite the low glycogen concentration of the light-small platelet population (which serves to offset this ratio in the opposite direction). (In this group of glycogen experiments, the heavy/light glycogen content ratio was greater than that noted in Table I.)

Resistance to osmotic shock. The above data suggested the possibility that the large-heavy platelets were equipped with greater metabolic potential to cope with their external environment and that these may be "younger" platelets. This hypothesis was tested by kinetic platelet survival studies of extreme density-volume platelet populations (see below) and by the relative ability of large-heavy vs. light-small platelets to resist osmotic shock.

Separate platelet populations were subjected to low ionic strength $\mathrm{NaCl}$ solutions in the presence of $5 \mathrm{~mm}$ glucose for $5 \mathrm{~min}$ at $37^{\circ} \mathrm{C}$. From the data in Fig. 2 it is apparent that the small-light platelet population was much more sensitive to osmotic shock with respect to the extracellular release of materials absorbing at 280 and $260 \mathrm{~m} \mu$, as well as the release of enzymatically determined ADP and ATP. ATP and ADP data are expressed as micromoles $\times 10^{-2}$ per milliliter of $5 \%$ platelet suspension and consequently represent $a b-$ solute differences between platelet populations. Since the extinction coefficient at $260 \mathrm{~m} \mu, 30^{\circ} \mathrm{C}$ for $1 \mathrm{~mm}$ ATP or ADP is 14.6 , it is apparent that considerably more (four times as much) $260 \mathrm{~m} \mu$ absorbance material is being released from platelets than can be accounted for

TABLE V

Incorporation of Leucine ${ }^{-14} C$ into a Platelet Lipid Extract*

\begin{tabular}{|c|c|c|c|c|c|c|}
\hline $\begin{array}{l}\text { Extracellula } \\
\text { concentratic }\end{array}$ & & $\begin{array}{l}\text { Light } \\
15 \% \ddagger\end{array}$ & $\begin{array}{l}\text { Total } \\
100 \%\end{array}$ & $\begin{array}{l}\text { Heavy } \\
17 \%\end{array}$ & $\begin{array}{l}\text { Heavy/light } \\
\text { ratio }\end{array}$ & $\begin{array}{l}\text { Platelet volume } \\
\text { ratio }\end{array}$ \\
\hline \multirow{3}{*}{$2 \mu \mathrm{m} / \mathrm{ml}$} & Lipid mg per platelet & 20.5 & 33.1 & 51.7 & 2.52 & 2.40 \\
\hline & cpm per platelet & 9990 & 16,038 & 27,243 & 2.73 & 2.40 \\
\hline & cpm per mg lipid & 487 & 485 & 527 & 1.09 & \\
\hline
\end{tabular}

* Data are expressed per platelet $\times 10^{-11}$ or as cpm per mg lipid. Each measurement represents the average of four to five experiments which were both incubated and assayed for radioactivity in duplicate. SEM was less than $10 \%$. $\ddagger$ Refers to the relative volume of the particular platelet population with respect to the total population. 
TABLE VI

Incorporation of Glucose ${ }^{-14} C$ into a

Platelet Lipid Extract*

\begin{tabular}{lrrrrr}
\hline & $\begin{array}{c}\text { Light } \\
15 \% \ddagger\end{array}$ & $\begin{array}{c}\text { Total } \\
100 \%\end{array}$ & $\begin{array}{c}\text { Heavy } \\
19 \%\end{array}$ & $\begin{array}{c}\text { Heavy/ } \\
\text { light } \\
\text { ratio }\end{array}$ & $\begin{array}{c}\text { Platelet } \\
\text { volume } \\
\text { ratio }\end{array}$ \\
\hline $\begin{array}{l}\text { Lipid, mg } \\
\text { per platelet }\end{array}$ & 21.9 & 36.0 & 52.5 & 2.40 & 2.41 \\
$\begin{array}{l}\text { cpm/per } \\
\text { platelet }\end{array}$ & 4023 & 7092 & 10,377 & 2.58 & 241 \\
$\begin{array}{c}\text { cpm/mg lipid } \\
\text { ppm }\end{array}$ & 184 & 197 & 197 & 1.07 & \\
\hline
\end{tabular}

* Data are expressed per platelet $\times 10^{-11}$ or as cpm per $\mathrm{mg}$ lipid. Each measurement represents the average of four experiments which were both incubated and assayed for radioactivity in duplicate. SEM was less than $10 \%$.

$\ddagger$ Refers to the relative volume of the particular platelet population with respect to the total population.

by measurable ATP and ADP release. This material could represent further breakdown products of ADP, as well as other material absorbing at $260 \mathrm{~m} \mu$.

Isotopic platelet survival data in rabbit platelet populations. After in vivo labeling of rabbit platelets with
TABLE VII

Incorporation of Glucose $e^{-14} C$ into Glycogen*

\begin{tabular}{lccccc}
\hline & $\begin{array}{c}\text { Light } \\
26 \% \ddagger\end{array}$ & $\begin{array}{c}\text { Total } \\
100 \%\end{array}$ & $\begin{array}{c}\text { Heavy } \\
21 \%\end{array}$ & $\begin{array}{c}\text { Heavy/ } \\
\text { light } \\
\text { ratio }\end{array}$ & $\begin{array}{c}\text { Platelet } \\
\text { volume } \\
\text { ratio }\end{array}$ \\
\hline $\begin{array}{c}\text { Glycogen, } \\
\mu \text { m per } \\
\text { platelet }\end{array}$ & 9.20 & 35.3 & 73.7 & 8.01 & 2.42 \\
$\begin{array}{c}\text { cpm per } \\
\text { platelet }\end{array}$ & 427 & 2849 & 5841 & 13.70 & 2.42 \\
$\begin{array}{c}\text { cpm/ } \mu \text { m } \\
\text { glycogen }\end{array}$ & 46.4 & 80.7 & 79.3 & 1.71 & \\
\hline
\end{tabular}

* Data are expressed per platelet $\times 10^{-11}$ or as cpm per $\mu$ mole glycogen. Each measurement represents the average of four experiments which were incubated in singlicate and measured for radioactivity and glycogen in duplicate. SEM was less than $10 \%$.

$\ddagger$ Refers to the relative volume of the particular platelet population with respect to the total population.

$\mathrm{DFP}^{2 a}$, platelet populations were separated into two extreme density populations, sp gr 1.0564 and 1.0480 for heavy-large and light-small platelets, respectively, on

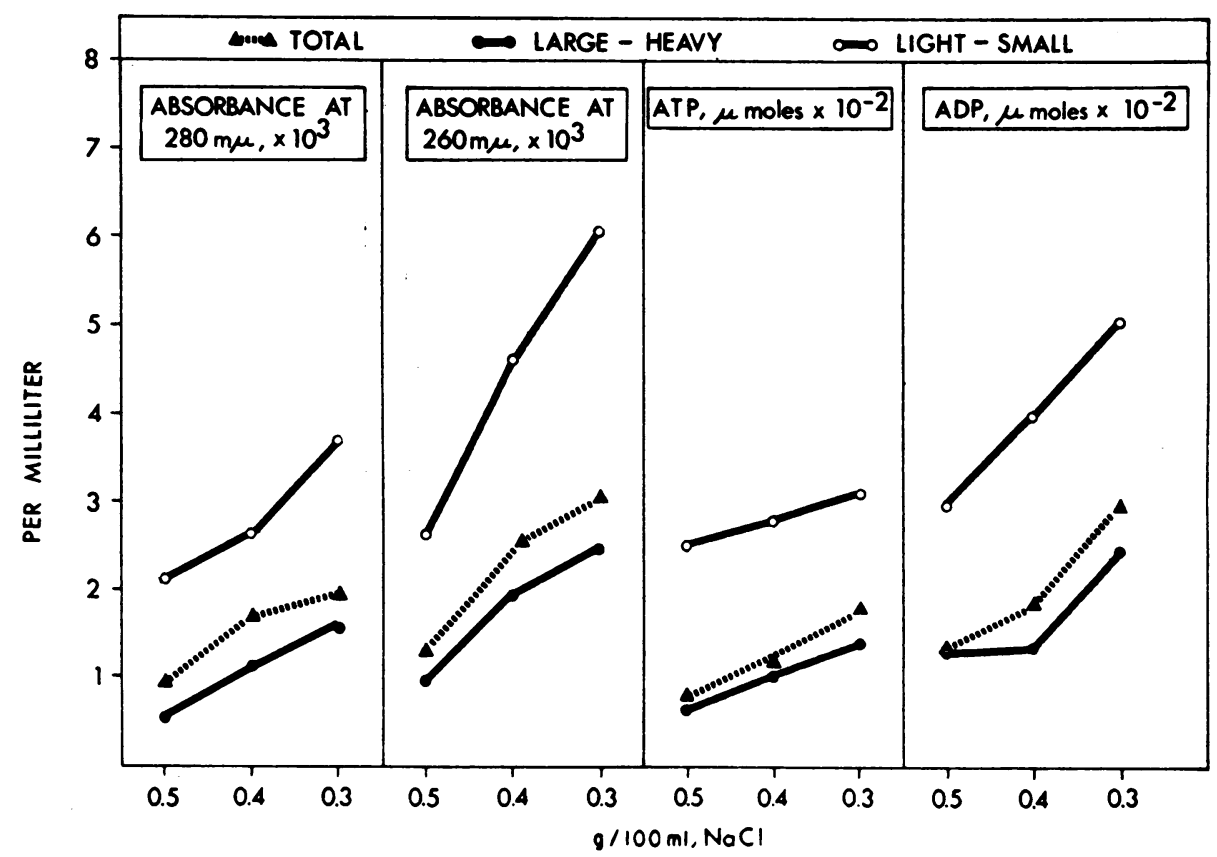

Figure 2 Resistance of separate platelet populations to osmotic shock. A $5 \%$ platelet suspension was exposed to $0.3,0.4$, and $0.5 \mathrm{~g} / 100 \mathrm{ml} \mathrm{NaCl}$ containing $5 \mathrm{~mm}$ glucose for $5 \mathrm{~min}$ at $37^{\circ} \mathrm{C}$. Release of material into the extracellular solution was measured with respect to 280 and $260 \mathrm{~m} \mu$ absorbance and with respect to ATP and ADP release. Data are expressed per milliliter of extracellular fluid. To obtain data per milliliter of platelets or per gram wet weight, divide by 0.05 . Data represent four different experiments assayed in triplicate. SEM was less than $10 \%$. 


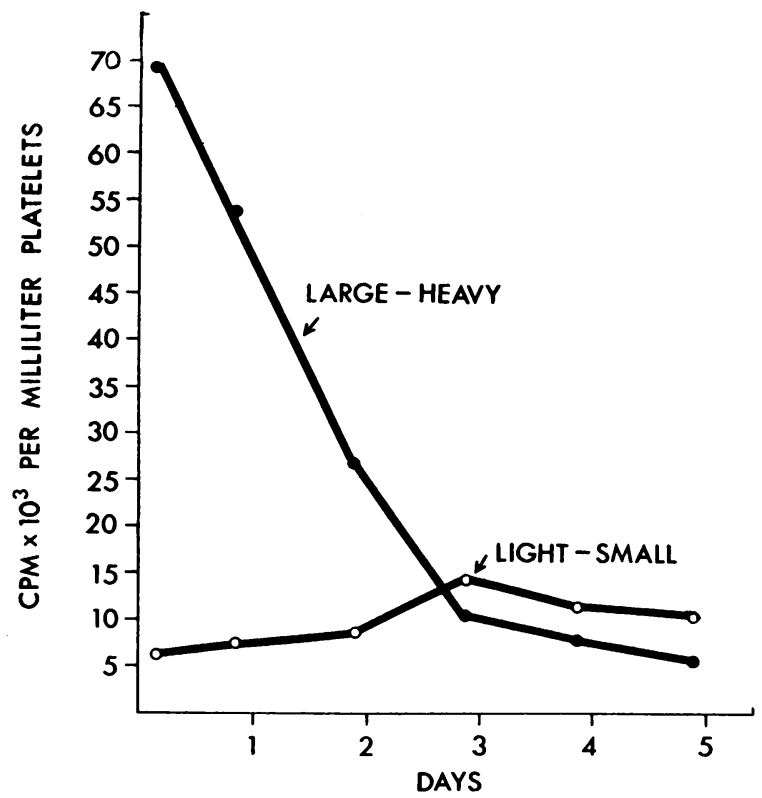

FIGURE 3 Isotopic platelet survival data in rabbit platelet populations. Six rabbits were labeled in vivo with $\mathrm{DFP}^{32}$, $0.072 \mathrm{mg} / \mathrm{kg}, 9.4 \mu \mathrm{c} / \mathrm{kg}$. On days $1-5$, animals were sacrificed by exsanguination and rabbit platelet-rich plasma prepared. Platelets were isolated into extreme density populations and assayed for radioactivity. Data are expressed as cpm per milliliter of packed platelets.

days 1-5. As can be noted from Fig. 3, light-small platelets incorporated considerably less radioactivity than did large-heavy platelets (e.g. 1/13 the amount of largeheavy platelets: $2 \mathrm{hr}$ postinjection of label). The label in the large-heavy platelet population declined approximately linearly for the 1 st 3 days, consistent with a senescent decay, and then decayed in a more curvilinear fashion. The label in the light-small platelet population increased slightly reaching a peak at approximately 3 days which then declined slightly. These data are entirely consistent with the theoretical curve which should be obtained if the large-heavy platelet population were a young platelet popukation which progressed to an older, light-small platelet population. It should be noted that the platelet populations isolated represent very young and very old platelets. Since the very old platelets would not be expected to remain in the circulation very long only a small increase in radioactivity would be expected for this fraction.

\section{DISCUSSION}

The average difference in volume between the largeheavy and light-small platelet populations was 2.3 -fold. The average volume of the total platelet population at room temperature was $7.5 \mu^{3}$, a value very similar to the $7.1 \mu^{3}$ obtained by a different method by Bull and
Zucker (21). The large-heavy platelet population contained more glycogen, orthophosphate, ATP, AMP, and protein than the small-light platelet population when expressed per gram wet weight or per milliliter packed platelets. Similarly, the large-heavy platelets have greater glycogen ${ }^{4}$ and protein synthesis, and more rapid glycogenolysis and glycolysis. These properties provide the large-heavy platelets with a metabolic advantage with respect to maintenance of cationic gradients (19) which require energy (22-25); maintenance of discoid shape $(12,26,27)$; as well as performance of physiologic function $(19,28-31)$. This supposition is supported by the observation that large-heavy platelets are considerably more resistant to osmotic lysis. The large-heavy platelet population may have a considerably greater metabolic advantage for the maintenance of cationic gradients than the slightly higher adenine nucleotide content would indicate for the following reason. If one were to consider the platelet as a sphere (actually it is intermediate between a sphere and a disc), a larger platelet would have less surface area per unit volume than a smaller platelet (i.e. the surface area of a sphere increases with the square of the radius whereas the volume increases with the cube of the radius). Consequently, a larger platelet would have more adenine nucleotide available per surface area for membrane ATPase activity than a small platelet with the same amount of adenine nucleotide content $(12,22-25)$ per unit volume. These large-heavy platelets also have a functional advantage over light-small platelets (results to be presented in the ensuing paper) with regard to platelet aggregation, and release and utilization of adenine nucleotide after simulated platelet-plug formation.

These data strongly suggest that large-heavy platelets are younger platelets, more recently released from the bone marrow, whereas light-small platelets are older platelets which have been in the circulation for several days. This supposition is consistent with the results obtained from kinetic $\mathrm{DFP}^{32}$ platelet-labeling experiments performed in rabbits and provides good evidence for a transition in vivo with age from large-heavy to lightsmall platelets. In this respect, an increased number of large platelets have frequently been observed during increased thrombopoiesis secondary to increased thrombocytolysis or blood loss (32). In a recent report, Karpatkin and Siskind (33) noted a two-fold increase in the per cent large platelets ${ }^{5}$ in patients with circulating

\footnotetext{
${ }^{4}$ Glycogen synthetase levels of heavy-large platelets (derived from $4000 \mathrm{~g}$ platelets extracts) were 1.8-fold greater than similar extracts prepared from light-small platelets. A similar investigation of total phosphorylase activity did not reveal significant differences between platelet populations (unpublished data).

${ }^{8}$ Refers to per cent large platelets (greater than $2.5 \mu$ in diameter) on peripheral smear of EDTA collected blood, stained with McNeil-Mallory tetrachrome.
} 
platelet antibody, but normal platelet counts. These authors postulated the existence of a compensated thrombocytolytic state in these patients. McDonald, Odell, and Gosslee (34), employing rat platelets, demonstrated a decrease in platelet size with age. Minter and Ingram (35) came to similar conclusions with dog platelets and noted that younger platelets were heavier after acute blood loss.

One must consider the possibility that the media employed to separate the two extreme density populations was responsible for the differences in metabolic activity observed. Several lines of evidence refute this possibility: (a) The mixture of butyl phthalate and hydrocarbon oils was metabolically inert when a control population was compared to a population processed through this mixture. (b) The platelets which traveled through the media were the large-heavy platelets, yet these were the most active metabolically, with the highest glycogen stores, and the most active functionally with respect to their physiologic and biochemical response to aggregating agents (36). The light-small platelets which remained on the surface of the oil were the most depleted metabolically as well as functionally. (c) Both largeheavy as well as light-small platelets produced lactate in a linear fashion for the $1 \mathrm{st} \mathrm{hr}$, an observation which is consistent with viability. Light-small platelets increased their glucose uptake to compensate for decreased glycogen and consequent decreased glycogenolysis. The retention of the regulatory mechanism for ATP generation indicates that complex metabolic functions are well preserved. $(d)$ Adenine nucleotide release of large-heavy as well as light-small platelets during control incubation conditions was minimal, similar to that of the total population (36) and similar to that reported previously (12). (e) The data obtained from the total population usually were intermediate between the large-heavy and small-light population-an observation which would again be consistent with a linear (senescent) progression from large-heavy to light-small platelets.

The practical aspects of these observations are apparent. Large platelets on peripheral smear or in wet preparations may conceivably be used as an index of young platelet populations and unusually active thrombopoiesis. Furthermore, the metabolic heterogeneity of human platelets supports the thesis that platelets die by senescence rather than random utilization and destruction.

\section{ACKNOWLEDGMENTS}

I am indebted to Doctors Aaron Kellner, Fred H. Allen, Jr., and Carlos Ehrich of The New York Blood Center for their cooperation in the supply of fresh platelet-rich plasma.

This work was supported by a research grant-in-aide from the New York Heart Association.

\section{REFERENCES}

1. Aster, R. H., and J. H. Jand1. 1964. Platelet sequestration in man. I. Methods. J. Clin. Invest. 43: 843.

2. Zucker, M. B., A. B. Ley, and K. Mayer. 1961. Studies on platelet life span and platelet depots by use of DFP J. Lab. Clin. Med. 58: 405.

3. Aas, K., and F. H. Gardner. 1958. Survival of blood platelets labeled with chromium ${ }^{\varpi}$. J. Clin. Invest. 37: 1257.

4. Odell, T. T., Jr., and B. Anderson. 1959. Production and lifespan of platelets. In Kinetics of Cellular Proliferation. F. Stohlman, Jr., editor. Grune \& Stratton Inc., New York. 278.

5. Lander, H., and M. G. Davey. 1964. The behaviour and survival of platelets in polycythaemia and thrombocythaemia. Australas. Ann. Med. 13: 207.

6. Leeksma, C. H. W., and J. A. Cohen. 1956. Determination of the life span of human blood platelets using labelled diisopropylfluorophosphonate. J. Clin. Invest. 35: 964.

7. Robinson, G. A., A. M. Bier, and A. McCarter. 1961. Labelling of blood platelets of the pig with $\left[{ }^{85} \mathrm{~S}\right]$ sulfate. Brit. J. Haematol. 7: 271.

8. Adelson, E., R. M. Kaufman, C. Berdeguez, A. A. Lear, and J. J. Rheingold. 1964. Platelet tagging with tritium labeled diisopropylfluorophosphate. Blood. 26: 744.

9. Murphy, E. A., G. A. Robinson, H. C. Rowsell, and J. F. Mustard. 1967. The pattern of platelet disappearance. Blood. 30: 26.

10. Bithell, T. C., J. W. Athens, G. E. Cartwright, and M. M. Wintrobe. 1967. Radioactive diisopropyl fluorophosphate as a platelet label: an evaluation of in vitro and in vivo technics. Blood. 29: 354.

11. Karpatkin, S. 1967. Studies on human platelet glycolysis. Effect of glucose, cyanide, insulin, citrate, and agglutination and contraction on platelet glycolysis. $J$. Clin. Invest. 46: 409.

12. Karpatkin, S., and R. M. Langer. 1968. Biochemical energetics of simulated platelet plug formation. Effect of thrombin, adenosine diphosphate, and epinephrine on intraand extracellular adenine nucleotide kinetics. $J$. Clin. Invest. $47: 2158$.

13. Lowry, O. H., J. V. Passonneau, F. X. Hasselberger, and D. W. Schulz. 1964. Effect of ischemia on known substrates and cofactors of the glycolytic pathway in brain. J. Biol. Chem. 239: 18.

14. Hassid, W. Z., and S. Abraham. 1957. Chemical procedures of analysis of polysaccharides. I. Determination of glycogen and starch. In Methods in Enzymology. S. P. Colowick and N. O. Kaplan, editors. Academic Press Inc., New York. 3: 34.

15. Karpatkin, S., E. Helmreich, and C. F. Cori. 1964 Regulation of glycolysis in muscle. II. Effect of stimulation and epinephrine in isolated frog sartorius muscle. J. Biol. Chem. 239: 3139.

16. Folch, J., M. Lees, and G. H. Sloane Stanley. 1957. A simple method for the isolation and purification of total lipids from animal tissues. J. Biol. Chem. 226: 497.

17. Bray, G. A. 1960. A simple efficient liquid scintillator for counting aqueous solutions in a liquid scintillation counter. Anal. Biochem. 1: 279.

18. Schneider, W. C. 1945. Phosphorus compounds in animal tissues. I. Extraction and estimation of desoxypentose nucleic acid and of pentose nucleic acid. J. Biol. Chem. $161: 293$.

19. Gorstein, F., H. J. Carroll, and E. Puszkin. 1967. Elec- 
trolyte concentrations, potassium flux kinetics, and the metabolic dependence of potassium transport in human platelets. J. Lab. Clin. Med. 70: 938.

20. Karpatkin, S., and A. Samuels. 1967. Effect of insulin and muscle contraction on protein synthesis in frog sartorius. Arch. Biochem. Biophys. 121: 695.

21. Bull, B. S., and M. B. Zucker. 1965. Changes in platelet volume produced by temperature, metabolic inhibitors, and aggregating agents. Proc. Soc. Exp. Biol. Med. 120: 296.

22. Dunham, E. T. 1957. Linkage of active cation transport to ATP utilization. Physiologist. 1: 23. (Abstr.)

23. Whittam, R. 1958. Potassium movements and ATP in human red cells. J. Physiol. 140: 479.

24. Hoffman, J. F. 1962. Cation transport and structure of the red cell plasma membrane. Circulation. 26: 1201.

25. Skou, J. C. 1965. Enzymatic basis for active transport of $\mathrm{Na}^{+}$and $\mathrm{K}^{+}$across cell membrane. Physiol. Rev. 45: 596.

26. Zucker, M. B., and J. Borrelli. 1954. Reversible alterations in platelet morphology produced by anticoagulants and by cold. Blood. 9: 602.

27. White, J., and W. Krivit. 1967. An ultrastructural basis for the shape changes induced in platelets by chilling. Blood. 30: 625.

28. Bettex-Galland, M., and E. F. Lüscher. 1960. Studies on the metabolism of human blood platelets in relation to clot retraction. Thromb. Diath. Haemorrh. 4: 178.
29. Mürer, E. H., A. J. Hellem, and M. C. Rozenberg. 1967. Energy metabolism and platelet function. Scand. J. Clin. Lab. Invest. 19: 280.

30. Rozenberg, M. C., and H. Holmsen. 1968. Adenine nucleotide metabolism of platelets. II. Uptake of adenosine and inhibition of ADP induced platelet aggregation. Biochim. Biophys. Acta. 155: 342.

31. Weissbach, H., and B. G. Redfield. 1961. Studies on the uptake of serotonin by platelets. In Blood Platelets. S. A. Johnson, R. W. Monto, J. W. Rebuck, and R. C. Horn, editors. Little, Brown \& Co., Inc., Boston. 393.

32. Wintrobe, M. M. 1962. Blood platelets and coagulation. In Clinical Hematology. Lea and Febiger Co., Philadelphia. 5th edition. 285.

33. Karpatkin, S., and G. W. Siskind. 1969. In vitro detection of platelet antibody in patients with idiopathic thrombocytopenic purpura and systemic lupus erythematosus. Blood. In press.

34. McDonald, T. P., T. T. Odell, Jr., and D. G. Gosslee. 1964. Platelet size in relation to platelet age. Proc. Soc. Exp. Biol. Med. 115: 684.

35. Minter, N., and M. Ingram. 1967. Density distribution of platelets. In Third Conference on Blood Platelets. Oak Ridge, Tenn. 26. (Abstr.)

36. Karpatkin, S. 1969. Heterogeneity of human platelets. II. Functional evidence suggestive of young and old platelets. J. Clin. Invest. 48: 1083. 